\title{
Estimating under-reporting of energy intake in dietary surveys using an individualised method
}

\author{
Kirsten L. Rennie ${ }^{1,2 *}$, Andy Coward ${ }^{1}$ and Susan A. Jebb ${ }^{1}$ \\ ${ }^{1}$ MRC Human Nutrition Research, Elsie Widdowson Laboratory, 120 Fulbourn Road, Cambridge CB1 9NL, UK \\ ${ }^{2}$ Unilever Corporate Research, Colworth Park, Sharnbrook, Bedford MK44 1LQ, UK
}

(Received 8 February 2006 - Revised 16 October 2006 - Accepted 10 November 2006)

\begin{abstract}
Under-reporting (UR) of energy intake (EI) by self-reported dietary methods is well-documented but the methods used to estimate UR in population-based studies commonly assume a sedentary lifestyle. We compared estimated UR using individualised estimates of energy requirements with a population cut-off based on minimum energy needs. UR was estimated for 1551 adults aged 19-64 years enrolled in the National Diet and Nutrition Survey. Physical activity diaries and $7 \mathrm{~d}$ weighed dietary records were completed concurrently. Mean daily EI (kJ/d) was calculated from the dietary records. Reported physical activity was used to assign each subject's activity level, and then to calculate estimated energy requirements (EER) from published equations. UR was calculated both as EER - EI with an adjustment for daily EER and EI variation, and also by a population method. By the individual method UR was approximately $27 \%$ of energy needs in men and $29 \%$ in women, with $75 \%$ of men and $77 \%$ of women classified as under-reporters; by the population method 80 and $88 \%$ were classified as under-reporters respectively. When subjects who reported their eating being affected by dieting or illness during dietary recording were excluded, UR was $25 \%$ of energy needs in both sexes. UR was higher in overweight and obese men and women compared with their lean counterparts $(P<0 \cdot 001)$. UR of EI must be considered in dietary surveys. The EER method allows UR to be quantified and takes into account an individual's activity level. Measures of physical activity and questions to identify under-eating during dietary recording may help to evaluate secular trends in UR.
\end{abstract}

Energy intake: Diet surveys: Under-reporting: Dietary record: Obesity

Assessments of diet in epidemiological studies are usually based on self-report methods but the validity of these methods is dependent on the accuracy with which participants record their dietary intake. Misreporting, particularly under-reporting (UR), of energy intake (EI) in self-reported dietary methods is a well-documented phenomenon (Prentice et al. 1986; Livingstone et al. 1990; Black et al. 1993). It has been observed in adults (Livingstone et al. 1990; Black et al. 1993) and children (Bandini et al. 1990; Livingstone et al. 1992; Bratteby et al. 1997) and it has been frequently observed to be greater in overweight and obese individuals than those of healthy weight (Prentice et al. 1986; Lichtman et al. 1992). The assessment of UR is therefore an important consideration when examining associations between EI, macronutrients, micronutrients or toxic substances in foods and excess weight gain and/or obesity-related diseases.

The doubly-labelled water (DLW) method provides an accurate measure of total energy expenditure (TEE) (Schoeller \& van Santen, 1982; Murgatroyd et al. 1993) which, on the assumption that TEE equals EI, can be used as an indirect biomarker of EI and used to determine the extent of UR in selfreport dietary measures (Schoeller, 2002; Livingstone \& Black, 2003). However, cost inhibits its use in large studies.
Assessing UR in population-based studies thus usually relies on predictions of TEE requirements. Most commonly, reported dietary intake is expressed as a multiple of BMR estimated from equations and a cut-off applied, below which subjects are identified as low-energy reporters (Goldberg et al. 1991). Although it can be applied to individuals, the 'Goldberg cut-off' technique was devised primarily to evaluate UR at a group level. It displays high sensitivity in identifying UR in sedentary subjects, but is limited in detecting UR in subjects with higher energy expenditures. This method introduces systematic bias in the assessment of UR since it assumes a sedentary lifestyle and low TEE and thus is not able to identify UR in individuals with high TEE.

The present study compares a method of estimating UR, using individualised estimates of energy requirements, against the Goldberg cut-off method in evaluating UR of EI in the 2000 National Diet and Nutrition Survey (NDNS) and against DLW measures of TEE in the NDNS feasibility study.

\section{Experimental methods}

The NDNS is a programme of cross-sectional surveys of different population age groups designed to be representative

\footnotetext{
Abbreviations: aPAL, activity physical activity level; DLW, doubly-labelled water; dPAL, dietary physical activity level; EER, estimated energy requirement; EI, energy intake; MET, metabolic equivalent; NDNS, National Diet and Nutrition Survey; TEE, total energy expenditure; UR, under-reporting.

* Corresponding author: Dr Kirsten L. Rennie, fax +44 1234 222161, email kirsten.rennie@unilever.com
} 
of Great Britain. This analysis uses the sample of adults aged 19-64 years studied in the NDNS 2000 and also the NDNS feasibility study undertaken in 200 adults in 1999.

\section{National Diet and Nutrition Survey: main survey}

This analysis includes 1551 adults from the NDNS main survey who had complete diet and physical activity diaries and anthropometric measurements. The sample design and method for the survey have been described in more detail elsewhere (National Diet and Nutrition Survey Technical Report; Social Survey Division of the Office of National Statistics et al. 2002).

\section{National Diet and Nutrition Survey feasibility study}

The feasibility study for the proposed NDNS survey of adults was carried out by the Social Survey Division of the Office of National Statistics and Medical Research Council Human Nutrition Research, with the University of Newcastle Dental School. The fieldwork for this feasibility study took place in 1999 before the main survey in order to test the feasibility of the proposed design and methods, including comparing the reported EI from the $7 \mathrm{~d}$ dietary record with TEE assessed by DLW to assess both the face and concurrent validity of the dietary assessment.

A sample of 200 subjects aged 19-64 years living in private households in Great Britain was selected. It was not representative of the population as a whole, but included equal numbers of men and women across the age groups in the main survey. Adults aged 19-64 years, not pregnant or breast-feeding, were eligible to take part. Eighty subjects were asked to undertake $10 \mathrm{~d}$ of DLW measurements whilst completing the $7 \mathrm{~d}$ dietary record and a physical activity diary. Seventy-six subjects agreed fully to the protocol (Social Survey Division of the Office of National Statistics et al. 2002) and data on EI and TEE from DLW were available for sixty-four subjects. Four subjects with fewer than $6 \mathrm{~d}$ of physical activity data were excluded from these analyses. The present analyses are therefore based on sixty subjects (thirty-nine women and twenty-one men) with complete data.

\section{Measurements}

The following measurements were undertaken in both the main NDNS and the NDNS feasibility study.

Reported energy intake. Subjects were asked to complete a $7 \mathrm{~d}$ weighed dietary record. This consisted of a 'home record' diary and an 'eating out' diary to record all food and drink items consumed at home or prepared at home but eaten elsewhere and all food and drink items consumed outside of the home respectively. All leftovers were described and weighed. Subjects were asked to record a full description of the item including brand name, where and when it was eaten, portion size and details of any leftovers. Further information on unweighed foods purchased from food outlets was obtained by interviewers. Where necessary, duplicate items were purchased in order to weigh the product. For food or drink purchased at the workplace or college, the interviewer visited the canteen and collected further information from the catering manager.
After the first $24 \mathrm{~h}$ of dietary recording, interviewers called on the subjects to ensure that recording was being undertaken correctly. The interviewer made at least one further visit during the recording week, with the total number of visits depending on how much support the subject appeared to need.

A food code list, containing over 6000 item codes, was prepared by the nutritionists for use by the interviewers. All items recorded were assigned a code, which were linked to a nutrient composition database to assign nutrient intakes for each item. Total energy $(\mathrm{kJ})$ consumed during the survey week from all food and drink items was calculated by nutritionists from the Office of National Statistics and mean daily EI computed. Further details of the recording and coding procedures can be found elsewhere (Henderson et al. 2002).

Anthropometric measurements. Interviewers measured each subject's weight and height. Subjects were classified as having a healthy weight (BMI $<25 \mathrm{~kg} / \mathrm{m}^{2}$ ), being overweight $\left(\right.$ BMI $\geq 25$ and $<30 \mathrm{~kg} / \mathrm{m}^{2}$ ) or obese $\left(\right.$ BMI $\left.\geq 30 \mathrm{~kg} / \mathrm{m}^{2}\right)$.

Physical activity. Subjects completed a physical activity diary concurrently with the $7 \mathrm{~d}$ dietary record. The subjects were asked to record, to the nearest $10 \mathrm{~min}$, how long they spent doing various activities on that day. This included time spent sleeping, walking, at work, participating in leisure-time and sports activities and any other activities not listed. The physical activity diary was adapted from a previous survey in young people and has not been validated against an objective measure of physical activity (Social Survey Division of the Office of National Statistics et al. 2002). Time spent daily in sleep, light, moderate and vigorous intensity activities was computed for each day of recording. The time spent in each type of activity was multiplied by a metabolic equivalent (MET) value to give total MET hours of activity per d. The MET value reflects the intensity of the activity as a multiple of one MET (Ainsworth et al. 1993, 2000). The MET values used were 1.0 for sleep, 2.0 for light-intensity, 3.5 for moderate-intensity and 6 for vigorousintensity activities. These were summed to give a mean MET score for the week and were then divided by $24 \mathrm{~h}$ to give an activity physical activity level (aPAL). The aPAL is a multiple of BMR and therefore represents the activity level of each subject as a ratio of BMR.

Estimated energy requirements and dietary physical activity level. Estimated energy requirements (EER) for each subject were calculated using the 2002 Institute of Medicine of the National Academies published Default (Institute of Medicine of the National Academies, 2002). The equations are sexand age-specific and are based on the age, weight and height of the subject and are derived from collated DLW energy expenditure data. They allow for four levels of activity; sedentary (aPAL $\geq 1.0<1.4$ ), low activity (aPAL $\geq 1.4<1.6$ ), active (aPAL $\geq 1.6<1.9$ ) and very active (aPAL $\geq 1.9$ $<2.5$ ) with a corresponding activity coefficient in the EER equations. The equations developed for use in lean to obese adults were used. Each subject was assigned an activity level based on his or her aPAL score and EER calculated. Dietary PAL (dPAL) was calculated as reported EI:BMR and expressed as this ratio.

\section{Estimated under-reporting}

In the NDNS feasibility study measurements of TEE from DLW were used to calculate the extent of UR (TEE - EI) 
for each subject. In the main NDNS, no measures of TEE by DLW were undertaken and therefore two different methods were used to estimate potential UR in this population. The two estimation methods were also applied to the NDNS feasibility study so that they could be compared with the gold standard UR measure using DLW.

The first estimation method calculated the number of under-reporters using the established Goldberg cut-off based on dPAL (Goldberg et al. 1991). This cut-off is a population-based method that takes into account the size of the sample population and the number of days of dietary intake records. In the present study the value using the lower $95 \%$ CI was applied. This lower confidence limit represents the value below which it is statistically unlikely that the reported mean intake represents either 'habitual' intake or a low intake obtained by chance. For the main NDNS this was dPAL $<1.54$ and for the NDNS feasibility study was dPAL $<1.48$, the differences reflecting differences in sample size.

The second method used the EER predictive Default (EER reported EI) for each individual in $\mathrm{kJ} / \mathrm{d}$. Since normal day-to-day variation in EI and in energy expenditure exists, exact agreement between EI and expenditure over $7 \mathrm{~d}$ in an individual is unlikely. Therefore confidence limits of agreement between reported EI and EER, and thus the limitations of EER for identifying under-reporters at the individual level need to be calculated, using the method described by Black \& Cole (2000). This is calculated as follows:

$$
\mathrm{CV}_{\mathrm{t}}=\sqrt{ }\left(\mathrm{CV}_{\mathrm{EE}}^{2}+\mathrm{CV}_{\mathrm{EI}}^{2} / \mathrm{d}\right),
$$

where $\mathrm{CV}_{\mathrm{t}}$ is the $\mathrm{CV}$ for both energy expenditure and $\mathrm{EI}, \mathrm{d}$ is the number of days of dietary recording and $\mathrm{CV}_{\mathrm{EE}}$ and $\mathrm{CV}_{\mathrm{EI}}$ are the $\mathrm{CV}$ for energy expenditure and EI respectively.

The $\mathrm{CV}_{\mathrm{EI}}$ calculated from the NDNS feasibility study was $27.9 \%$ and the $\mathrm{CV}_{\mathrm{TEE}}$ for TEE measured by DLW was taken from DLW studies of $7 \mathrm{~d}$ duration $(8.2 \%)$ (Black \& Cole, 2000). This gave a total value $\left(\mathrm{CV}_{t}\right)$ of $13.4 \%$. The $\mathrm{CV}_{\mathrm{EI}}$ calculated from the main NDNS was $31 \%$, and since the EER equations were based on DLW studies, the $\mathrm{CV}_{\mathrm{EE}}$ for EER was also taken from DLW studies of $7 \mathrm{~d}$ duration $(8.2 \%)$. This gave a $C_{t}$ of $14.3 \%$ for the main NDNS.

\section{Illness and dieting during the survey recording period}

In the main NDNS subjects were asked for each day of the recording period, 'did illness affect your eating?'. These questions were coded and a binary variable on whether illness affected eating during the $7 \mathrm{~d}$ recording period was calculated for each subject. In the main survey fifty-one (7\%) men and $126(15 \%)$ women reported that their eating was affected by illness during the recording period. Subjects who reported that they were dieting to lose weight during the recording period were also identified (eighty-one men and 202 women). This information was not available for the NDNS feasibility study.

In the main NDNS, all analyses were undertaken with and without two groups of subjects whose eating was affected by either illness or self-reported dieting during the period of diet recording.

\section{Statistical methods}

Positive differences between EER and reported EI are described here as $\mathrm{UR}_{\mathrm{EER}}$ and between TEE and reported EI as $\mathrm{UR}_{\mathrm{TEE}}$. Results for anthropometric variables and physical activity levels are expressed as mean values and standard deviations and for non-parametric variables, such as estimated UR $(\mathrm{kJ} / \mathrm{d})$, which could not be normalised, as medians and interquartile ranges. Inter-individual differences in the extent of UR, EI and energy expenditure were assessed using the Mann-Whitney $U$ test and Kruskal-Wallis one-way ANOVA to test for differences between age groups and BMI status. Pearson $\chi^{2}$ was used to test for differences between the number of subjects identified as under-reporters by each method. In the main NDNS in the absence of a gold standard measure, the two methods of identifying UR were compared by calculating the positive and negative predictive value. Values of $P<0.05$ were regarded as statistically significant and all statistical analyses were performed using SPSS (version 11.0; SPSS Inc., Chicago, IL, USA).

\section{Results}

\section{National Diet and Nutrition Survey feasibility study}

The mean age was 43 (SD 10.2) years in men and 43 (SD 12.7) years in women. The prevalence of obesity was $14 \%$ in men and $18 \%$ in women with a mean BMI of $26 \cdot 3$ (SD 3.1) and $26.9(\mathrm{SD} 5.8) \mathrm{kg} / \mathrm{m}^{2}$ in men and women respectively. Reported EI and TEE measured by DLW were significantly higher in men than in women (EI 11.4 v. $8.3 \mathrm{MJ} / \mathrm{d}$ respectively $(P<0.001)$; TEE 13.7 v. $10 \cdot 0 \mathrm{MJ} / \mathrm{d}$ respectively $(P<0.001))$.

When TEE was measured by DLW, there was evidence of UR in both men and women (median $\mathrm{UR}_{\mathrm{TEE}}$ : men 1935 (interquartile range 804, 4365) $\mathrm{kJ} / \mathrm{d}$, women 1485 (interquartile range 895,3571$) \mathrm{kJ} / \mathrm{d}$ ). When estimated, $\mathrm{UR}_{\mathrm{EER}}$ was not significantly different between the sexes when expressed as a percentage of energy needs $(100 \times(\mathrm{EER}-$ reported EI)/EER $)$, equating to a median 18 and $19 \%$ of energy needs in men and women respectively. There were no significant differences in the degree of $U_{\mathrm{TEE}}$ with age or with obesity status in this small sample (data not shown). No subjects were identified as over-reporters by either the DLW or EER method.

Estimated UR $\mathrm{EER}_{\mathrm{E}}$ and UR using the Goldberg method were not significantly different from measured $\mathrm{UR}_{\mathrm{TEE}}$ in either men or women. We undertook a sensitivity and specificity analysis for each method compared with the TEE measured by DLW. Sensitivity of the EER method compared with TEE measurements was $75 \%$ in men and $92 \%$ in women and specificity was $78 \%$ in men and $67 \%$ in women. By measured TEE $57 \%$ of men and $62 \%$ of women were identified as underreporters, by the Goldberg cut-off method $62 \%$ of men and $77 \%$ of women and by the EER method, $52 \%$ of men and $69 \%$ of women respectively. These proportions by the different UR methods were not statistically different.

\section{Main National Diet and Nutrition Survey}

A total of 1612 subjects had valid weight and height measurements from which to calculate BMI. Complete data were available for 696 men and 855 women. Age was 42 (SD 12) years in both men and women and BMI was $27 \cdot 1$ (SD $4 \cdot 3) \mathrm{kg} / \mathrm{m}^{2}$ 
in men and 26.5 (SD 5.7) $\mathrm{kg} / \mathrm{m}^{2}$ in women. The prevalence of obesity was $24 \%$ in men and $21 \%$ in women. There were no significant differences between the main NDNS and the feasibility study in these characteristics.

EI was significantly higher in men than in women $(9.8 v$. $7.0 \mathrm{MJ} / \mathrm{d}$ respectively; $P<0.001)$ and significantly lower than the reported EI in the feasibility study in both men and women $(P<0 \cdot 001)$. There was no association between reported EI with age group or with BMI status in men. These observations were unchanged when those reporting to be dieting or ill during the recording period were excluded (Tables 1 and 2). However, in women, reported EI was significantly lower in older women $(P=0.047)$ and in those that were overweight or obese compared with their lean counterparts $(P=0.02)$. When those who reported dieting or being ill during the recording period were removed, these associations with age and weight status in women were no longer significant (Table 2).

EER calculated from the 2002 published equations were significantly higher in men than in women (median 13281 v. $9770 \mathrm{~kJ} / \mathrm{d}$ respectively; $P<0.001$ ), decreased significantly in the older age groups $(P<0.001$; Table 1$)$ and were higher in overweight and obese subjects compared with their lean counterparts $(P<0.001$; Table 2$)$. dPAL was significantly higher in men than women (men 1.29 (SD 0.34); women 1.19 (SD 0.32); $P<0.001$ ). Women in the older age groups had significantly higher $\mathrm{dPAL}$ than those in the younger age groups $(P=0 \cdot 02)$, but no association with age was found in men (Table 1). dPAL was significantly lower in overweight and obese men and women compared with their lean counterparts $(P<0.001$ in men and women; Table 2$)$. When those who reported dieting or being ill during the recording period were removed, the higher dPAL in men compared with women remained (men 1.33 (SD 0.32), women 1.26 (SD $0.31) ; \quad P<0.001)$. However, the significant relationship observed in women between dPAL and age group was no longer apparent when those who reported dieting or being ill were removed and was also not observed in men (Table 1). However, the significant associations observed between the sexes and with weight status remained $(P<0.001)$ (Table 2$)$.

Median estimated $\mathrm{UR}_{\mathrm{EER}}$ was $3503 \mathrm{~kJ} / \mathrm{d}$ in men and $2827 \mathrm{~kJ} / \mathrm{d}$ in women, equivalent to a median $27 \%$ of energy needs in men and $29 \%$ in women. Expressed as absolute EI $(\mathrm{kJ} / \mathrm{d})$, estimated $\mathrm{UR}_{\mathrm{EER}}$ was significantly higher in men than women $(P<0 \cdot 001)$, but higher in women when expressed as a percentage of energy needs $(P=0 \cdot 03)$. Only twenty-six $(1.6 \%)$ subjects (fifteen men and eleven women) were classified as over-reporters. $\mathrm{UR}_{\mathrm{EER}}$ was lower in the older age groups in both men and women $(P<0 \cdot 001$; Fig. 1$)$ and significantly higher in overweight and obese men and women compared with their lean counterparts $(P<0 \cdot 001$; Fig. 2). When those subjects who reported being unwell or dieting to lose

Table 1. Reported energy intake (EI), estimated energy requirements (EER) and dietary physical activity level (dPAL) by age group in the National Diet and Nutrition Survey

(Medians and interquartile ranges; IQR)

\begin{tabular}{|c|c|c|c|c|c|c|c|c|}
\hline \multirow[t]{2}{*}{ Age... } & \multicolumn{2}{|c|}{$19-24$ years } & \multicolumn{2}{|c|}{$25-34$ years } & \multicolumn{2}{|c|}{$35-49$ years } & \multicolumn{2}{|c|}{$50-64$ years } \\
\hline & Median & IQR & Median & IQR & Median & IQR & Median & IQR \\
\hline \multicolumn{9}{|c|}{ El $(M J / d)$} \\
\hline \multicolumn{9}{|c|}{ Totalt ( $n$ 1551) } \\
\hline Men & 9.4 & $8 \cdot 6,11 \cdot 1$ & $9 \cdot 8$ & $8 \cdot 2,11 \cdot 4$ & $9 \cdot 9$ & $8 \cdot 5,11 \cdot 4$ & $9 \cdot 6$ & $8 \cdot 0,11 \cdot 1$ \\
\hline Women* & $7 \cdot 2$ & $5 \cdot 9,8 \cdot 3$ & $6 \cdot 7$ & $5 \cdot 2,7.9$ & $7 \cdot 1$ & $5 \cdot 9,8 \cdot 1$ & $7 \cdot 0$ & $6 \cdot 0,8 \cdot 2$ \\
\hline \multicolumn{9}{|c|}{ With exclusions $\ddagger$ ( $n$ 1133) } \\
\hline Men & 9.5 & $8.3,11.5$ & $9 \cdot 8$ & $8 \cdot 3,11 \cdot 4$ & $10 \cdot 2$ & $8.9,11.6$ & 9.9 & $8 \cdot 5,11 \cdot 1$ \\
\hline Women & $7 \cdot 7$ & $6 \cdot 3,8 \cdot 4$ & $6 \cdot 9$ & $6 \cdot 0,8 \cdot 1$ & 7.4 & $6 \cdot 2,8 \cdot 3$ & $7 \cdot 2$ & $6 \cdot 3,8 \cdot 3$ \\
\hline \multicolumn{9}{|c|}{ EER $(M J / d)$} \\
\hline \multicolumn{9}{|c|}{ Total‡ $(n$ 1551) } \\
\hline$M e n^{\star *}$ & $14 \cdot 0$ & $12 \cdot 5,15 \cdot 4$ & 13.9 & $12 \cdot 7,15 \cdot 4$ & 13.5 & $12 \cdot 3,14 \cdot 8$ & $12 \cdot 3$ & $11 \cdot 5,13.8$ \\
\hline Women** & $10 \cdot 6$ & $9 \cdot 4,11 \cdot 4$ & 9.9 & $9 \cdot 3,10 \cdot 7$ & $10 \cdot 0$ & $9 \cdot 2,10 \cdot 7$ & $9 \cdot 3$ & $8 \cdot 6,10 \cdot 0$ \\
\hline \multicolumn{9}{|c|}{ With exclusions $\ddagger(n 1133)$} \\
\hline$M e n^{\star \star}$ & $13 \cdot 8$ & $12 \cdot 5,14 \cdot 6$ & $13 \cdot 8$ & $12 \cdot 6,15 \cdot 4$ & 13.5 & $12 \cdot 2,14 \cdot 6$ & $12 \cdot 3$ & $11.5,13.9$ \\
\hline Women** & $10 \cdot 4$ & $9 \cdot 4,11 \cdot 2$ & $9 \cdot 8$ & $9 \cdot 2,10 \cdot 6$ & $10 \cdot 0$ & $9 \cdot 2,10 \cdot 6$ & $9 \cdot 3$ & $8 \cdot 5,10 \cdot 0$ \\
\hline \multicolumn{9}{|c|}{ dPAL } \\
\hline \multicolumn{9}{|c|}{ Total† ( $n$ 1551) } \\
\hline \multicolumn{9}{|c|}{ Men } \\
\hline Mean & & 1.25 & & 1.28 & & 1.30 & & 1.28 \\
\hline SD & & 0.30 & & 0.34 & & 0.35 & & 0.33 \\
\hline \multicolumn{9}{|l|}{ Women } \\
\hline Mean* & & $1 \cdot 17$ & & $1 \cdot 13$ & & $1 \cdot 21$ & & 1.23 \\
\hline SD & & 0.35 & & 0.30 & & 0.33 & & 0.30 \\
\hline \multicolumn{9}{|c|}{ With exclusions $\ddagger$ ( $n$ 1133) } \\
\hline \multicolumn{9}{|c|}{ Men } \\
\hline Mean & & $1 \cdot 28$ & & 1.29 & & 1.35 & & 1.33 \\
\hline SD & & 0.31 & & 0.33 & & 0.34 & & 0.31 \\
\hline \multicolumn{9}{|l|}{ Women } \\
\hline Mean & & 1.27 & & 1.21 & & 1.27 & & 1.28 \\
\hline SD & & 0.35 & & 0.28 & & 0.31 & & 0.30 \\
\hline
\end{tabular}

Trend was significant: * $P<0.05,{ }^{* *} P<0.001$.

†Total sample population.

‡Excluding those who reported dieting or whose eating was affected by illness during the recording period. 
Table 2. Reported energy intake (EI), estimated energy requirements (EER) and dietary physical activity level (dPAL) by weight status in the National Diet and Nutrition Survey

(Medians and interquartile ranges; IQR)

\begin{tabular}{|c|c|c|c|c|c|c|}
\hline \multirow[t]{2}{*}{ Weight status... } & \multicolumn{2}{|c|}{ Lean } & \multicolumn{2}{|c|}{ Overweight } & \multicolumn{2}{|c|}{ Obese } \\
\hline & Median & IQR & Median & IQR & Median & IQR \\
\hline \multicolumn{7}{|l|}{$\mathrm{El}(\mathrm{MJ} / \mathrm{d})$} \\
\hline \multicolumn{7}{|l|}{ Total† ( $n$ 1551) } \\
\hline Men & $9 \cdot 6$ & $8 \cdot 4,11 \cdot 3$ & $9 \cdot 8$ & $8 \cdot 3,11 \cdot 2$ & $10 \cdot 1$ & $8 \cdot 0,11 \cdot 4$ \\
\hline Women* & $7 \cdot 2$ & $6 \cdot 1,8 \cdot 2$ & $6 \cdot 7$ & $5 \cdot 7,7 \cdot 9$ & $6 \cdot 6$ & $5 \cdot 5,8 \cdot 1$ \\
\hline \multicolumn{7}{|c|}{ With exclusions $¥(n$ 1133) } \\
\hline Men & $9 \cdot 7$ & $8 \cdot 5,11.4$ & $9 \cdot 9$ & $8 \cdot 5,11 \cdot 3$ & $10 \cdot 3$ & $8 \cdot 8,11 \cdot 6$ \\
\hline Women & $7 \cdot 4$ & $6 \cdot 3,8 \cdot 2$ & $7 \cdot 1$ & $6 \cdot 2,8 \cdot 2$ & $7 \cdot 0$ & $6 \cdot 0,8.5$ \\
\hline \multicolumn{7}{|l|}{ EER $(\mathrm{MJ} / \mathrm{d})$} \\
\hline \multicolumn{7}{|l|}{ Total† ( $n$ 1551) } \\
\hline Men** & 12.5 & $11 \cdot 6,13 \cdot 8$ & $13 \cdot 2$ & $12 \cdot 1,14 \cdot 5$ & $14 \cdot 6$ & $13 \cdot 3,16 \cdot 4$ \\
\hline Women** & $9 \cdot 4$ & $8 \cdot 8,10 \cdot 1$ & $9 \cdot 8$ & $9 \cdot 1,10 \cdot 6$ & $10 \cdot 7$ & $9 \cdot 9,11 \cdot 7$ \\
\hline \multicolumn{7}{|c|}{ With exclusions $¥$ ( $n$ 1133) } \\
\hline Men $^{\star \star}$ & $12 \cdot 6$ & $11 \cdot 7,13.9$ & $13 \cdot 2$ & $12 \cdot 2,14 \cdot 6$ & $14 \cdot 6$ & $13 \cdot 4,16 \cdot 2$ \\
\hline Women ${ }^{\star \star}$ & $9 \cdot 4$ & $8 \cdot 8,10 \cdot 1$ & $9 \cdot 8$ & $9 \cdot 2,10 \cdot 6$ & $10 \cdot 9$ & $10 \cdot 0,11 \cdot 9$ \\
\hline \multicolumn{7}{|l|}{$\mathrm{dPAL}$} \\
\hline \multicolumn{7}{|l|}{$\begin{array}{l}\text { Total† }(n \text { 1551) } \\
\text { Men }\end{array}$} \\
\hline \multicolumn{7}{|l|}{ Men } \\
\hline Mean** $^{\star *}$ & & 1.40 & & $1 \cdot 27$ & & $1 \cdot 17$ \\
\hline SD & & 0.35 & & 0.31 & & 0.34 \\
\hline \multicolumn{7}{|l|}{ Women } \\
\hline Mean** & & 1.29 & & $1 \cdot 15$ & & 1.05 \\
\hline SD & & 0.30 & & 0.30 & & 0.31 \\
\hline \multicolumn{7}{|c|}{ With exclusions $\ddagger$ ( $n$ 1133) } \\
\hline \multicolumn{7}{|c|}{ Men } \\
\hline Mean $^{\star *}$ & & 1.41 & & $1 \cdot 31$ & & 1.23 \\
\hline SD & & 0.35 & & $0 \cdot 30$ & & 0.30 \\
\hline \multicolumn{7}{|l|}{ Women } \\
\hline Mean** $^{\star *}$ & & 1.33 & & 1.23 & & $1 \cdot 12$ \\
\hline SD & & 0.29 & & 0.29 & & 0.34 \\
\hline
\end{tabular}

Trend was significant: * $P<0.05$, ${ }^{* *} P<0.001$.

†Total sample population.

$\ddagger$ Excluding those who reported dieting or whose eating was affected by illness during the recording period.

weight during the dietary recording period were excluded from the analysis, $\mathrm{UR}_{\mathrm{EER}}$ was still significantly higher in men than women in absolute terms $(3230$ v. $2384 \mathrm{~kJ} / \mathrm{d}$ respectively; $P<0.001)$ but there was no longer a difference between

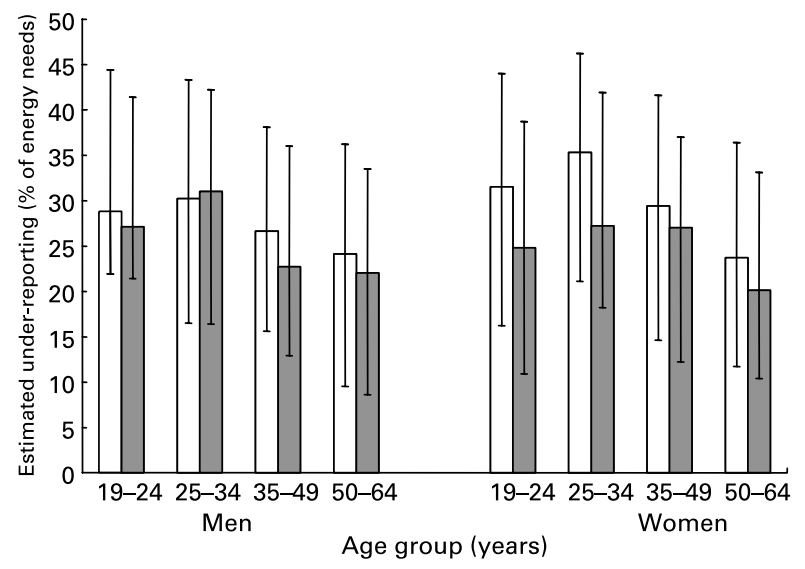

Fig. 1. Estimated under-reporting of energy needs by age group in the National Diet and Nutrition Survey in all subjects $(n 1551 ; \square)$ and excluding those who reported dieting or whose eating was affected by illness during the recording period $(n 1133 ; \mathbf{\square})$. Values are medians, with interquartile ranges represented by vertical bars. There was a significant trend in men and women in all subjects and with exclusions $(P<0.001)$. the sexes when expressed as a percentage of energy needs (men 25.0\%, women 24.6\%; NS). The same significant relationships were observed, as identified in the whole sample, with $\mathrm{UR}_{\mathrm{EER}}$ being lower in older age groups and higher in overweight and obese subjects compared with their lean counterparts $(P<0.001$; Figs. 1 and 2 respectively). When subjects who reported being unwell or dieting were excluded, the number of men and women identified as under-reporters was lower (Table 3).

Comparison of the $\mathrm{UR}_{\mathrm{EER}}$ method and Goldberg cut-off method showed that $89 \%$ of men and $88 \%$ of women identified as under-reporters by the $\mathrm{UR}_{\mathrm{EER}}$ method were also identified as under-reporters by the Goldberg method. When those subjects who reported being unwell or dieting were excluded, the agreement between the two methods was similar $(89 \%$ in men and $86 \%$ in women respectively). Similarly, $79 \%$ of men and $94 \%$ of women classified as adequate reporters by the EER method were also identified by the Goldberg cut-off, with little change when those unwell or dieting were excluded ( $80 \%$ of men and $96 \%$ of women respectively).

\section{Discussion}

In this analysis there was no difference in sensitivity and specificity between the Goldberg cut-off and EER method in classifying subjects as under-reporters or adequate reporters 


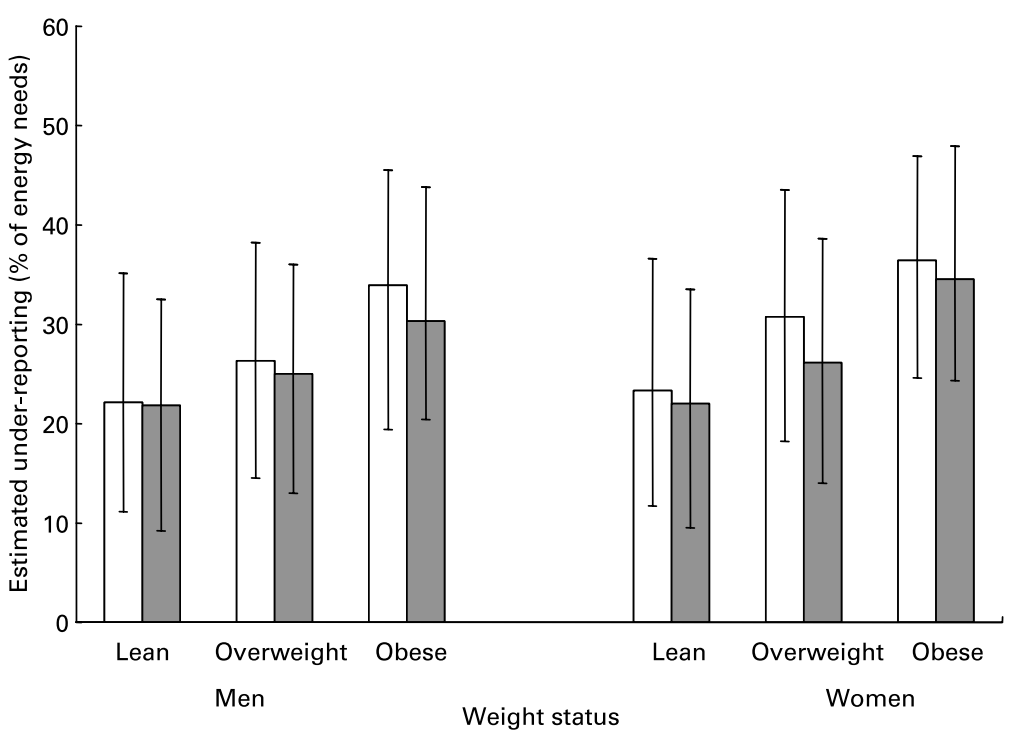

Fig. 2. Estimated under-reporting of energy needs by weight status in the National Diet and Nutrition Survey in all subjects $(n 1551 ; \square)$ and excluding those who reported dieting or whose eating was affected by illness during the recording period ( $n 1133$; $\mathbf{\square})$. Values are medians, with interquartile ranges represented by vertical bars. There was a significant trend in men and women in all subjects and with exclusions $(P<0.001)$.

(between 79 and 96\%). However, the EER method has advantages over the Goldberg cut-off method as it allows a quantification of UR of EI, producing a continuous variable that can be used in analyses, whereas with a cut-off the only option is to exclude subjects who are classified as under-reporters. Given the extent of UR in dietary surveys, exclusion of a large proportion of under-reporters identified by a cut-off may introduce considerable bias. In addition, the UR method with EER, using individual reported activity data to estimate energy requirements, could be more sensitive than generalised predictions, for example in comparing levels of UR between populations with different levels of physical activity. This allows an assessment of subject-specific bias that is useful in interpreting data from dietary surveys, particularly in determining secular trends in UR and EI in surveys.

In large dietary surveys the extent of UR can only be estimated since measuring TEE by the DLW method is not feasible. As in this national survey, the use of the DLW method is inhibited by the expense of the method. Furthermore, the introduction of this measure with additional participant burden into surveys, which are designed to be nationally representative, may lead to a less representative population sample and thus introduce bias. Therefore, in this survey

Table 3. Identification of under-reporters by different estimation methods in the National Diet and Nutrition Survey 2000 ( $n$ 1551)

\begin{tabular}{|c|c|c|}
\hline & Goldberg cut-off & EER method \\
\hline \multicolumn{3}{|l|}{ Men (\%) } \\
\hline Total $^{*}(n 696)$ & 79.5 & $75 \cdot 3$ \\
\hline With exclusionst ( $n$ 570) & $76 \cdot 8$ & $73 \cdot 2$ \\
\hline \multicolumn{3}{|l|}{ Women (\%) } \\
\hline Total $^{\star}(n 855)$ & 87.5 & $77 \cdot 3$ \\
\hline With exclusionst ( $n$ 563) & 83.8 & $72 \cdot 5$ \\
\hline
\end{tabular}

a feasibility study was undertaken before the main survey in which TEE was measured by DLW in a sub-sample to assess the level of UR. There was no difference in mean age, BMI or prevalence of obesity between the sub-sample in the feasibility study and the main survey. However, median reported EI was higher in the feasibility study sample than the main NDNS survey. This suggests that the level of UR or under-eating during the recording period may have been higher in the main survey compared with the feasibility study. A limitation of the present study is the estimation of TEE in the main survey rather than a direct measure of TEE by DLW. We have used predictive equations of energy requirements (Institute of Medicine of the National Academies, 2002) to estimate energy requirements in the main survey and have found the estimation of UR $\mathrm{EER}_{\mathrm{E}}$ using these equations comparable with $\mathrm{UR}_{\mathrm{TEE}}$ measured by DLW. The predictive equations themselves were based on DLW, which provides objective measures of TEE over a period of at least $7 \mathrm{~d}$. However, since $7 \mathrm{~d}$ measurements of EI and energy expenditure are not a true measure of habitual intake and expenditure, we have applied the lower $95 \%$ CI on the absolute values of UR to allow for day-to-day variation.

The EER equations allow adjustment for physical activity level, with four categories. We used data from the physical activity diary, which was completed concurrently with the weighed dietary record, to calculate aPAL for each individual to determine the most appropriate activity category on an individual basis. However, as with dietary intake, there is the potential that physical activity may be under- or over-reported or altered during the recording period. Over-reporting of physical activity is probably the primary concern in surveys and this may introduce positive bias. Despite this limitation, the sensitivity and specificity with measured UR $\mathrm{URE}_{\mathrm{TEE}}$ using DLW in the feasibility study suggest that this method gives a good estimate of the extent of UR in this population sample.

Huang et al. (2005) recently used these predictive equations to assess UR in a dietary survey of adults where diet was 
assessed by $24 \mathrm{~h}$ dietary recalls. However, since no measure of physical activity was made in this survey, the authors were not able to assign an activity level on an individual basis. By categorising all subjects as low active, they reported that reported EI as a percentage of EER varied considerably with UR estimated as $19.1 \%$ of EER and as $4.6 \%$ of EER if a 1.0 SD cutoff was applied.

Using individualised EER, analyses from the present study suggest that there is substantial UR of EI in the NDNS, equivalent to $27 \%$ of energy needs in men and $29 \%$ in women. After excluding those subjects who reported their eating being affected by dieting or illness during the recording period, UR was approximately $25 \%$ of energy needs in both men and women, with $73 \%$ of men and women categorised as 'under-reporters'. As reported in other studies, we observed higher UR in overweight and obese adults compared with those of healthy weight (Prentice et al. 1986; Lichtman et al. 1992; Heitmann \& Lissner, 1995; Voss et al. 1998), with estimated UR as percentage of energy needs being $39 \%$ and $57 \%$ higher in obese men and women respectively compared with their lean counterparts. In a review of DLW studies, mean UR of energy in normal-weight adults was 16 (range 0-25) $\%$, whereas in obese subjects it was two-fold (41 (range 25-50) \%) (Westerterp \& Goris, 2002). When reported EI was expressed as a ratio of BMR (dPAL), we found the ratio was lower in women than in men and in overweight and obese individuals than those of healthy weight, reaching physiologically implausible levels in overweight and obese women in particular. However, in the present study it is not possible to determine whether obese individuals systematically under-report specific foods than their lean counterparts or proportionately under-report all foods. This confounds attempts to analyse dietary factors associated with obesity.

An assessment of UR in the NDNS of young people in 1997 , estimated using similar methods, found that young individuals under-reported their EI by $20-21 \%$ of energy needs (Rennie et al. 2005). The extent of UR in the NDNS is comparable with other studies. A review of DLW validation studies of reported intake found UR of EI in free-living adults was substantial but individually variable, with a mean reported EI of $>20 \%$ below TEE (Livingstone \& Black, 2003). Expressed as a percentage of energy needs, $U_{\mathrm{EER}}$ was significantly higher in women, but when expressed as absolute values was higher in men, reflecting their higher energy needs. In contrast, a review of DLW found no difference between the sexes when expressed as absolute values (kJ/d) (Westerterp \& Goris, 2002).

Comparison with the 1986-7 Dietary and Nutritional Survey of British Adults shows that reported EI has not increased between the 1986-7 and the 1997 survey (Pryer et al. 1997). Mean EI were $10.3 \mathrm{MJ} / \mathrm{d}$ in men and $7 \cdot 0 \mathrm{MJ} / \mathrm{d}$ in women in $1986-7$ and $9.8 \mathrm{MJ} / \mathrm{d}$ in men and $7.0 \mathrm{MJ} / \mathrm{d}$ in women in NDNS. The absence of an increase in reported EI has also been observed in US dietary surveys (Borrud et al. 1997; Norris et al. 1997), which could be interpreted as evidence that decreasing activity lies at the root of the rising prevalence of obesity. However, this does not take into account a possible increasing trend of UR of EI over time.

Mean dPAL reported in population-based studies in the last two decades ranges from 1.22 to 1.48 in women and 1.38 and 1.58 in men (Smith et al. 1994; Briefel et al. 1997; Lafay et al.
1997; Pryer et al. 1997; Johansson et al. 1998), with no apparent trend in dPAL values. However, to investigate secular trends in UR, a measure of physical activity concurrent with the dietary recording is necessary. Unfortunately there are no objective data available on which to evaluate secular trends in physical activity.

The under-estimation of EI in comparison with TEE or EER cannot distinguish between UR and under-eating during the recording period (Goris et al. 2000). Under-eating while recording food intake has been observed in lean and obese adults (Westerterp \& Goris, 2002), since subjects take the opportunity to change their eating behaviour during recording, particularly dieting to lose weight. This could be identified by weighing the subjects before and after the dietary recording period if the recording period is sufficiently long enough to detect weight changes rather than day-to-day fluctuations. To partially adjust for this, analyses were undertaken with the whole sample and then excluding those who reported to be trying to lose weight during the recording week. Second, there may be errors in the dietary intake measurements, including the weighing of food and liquid intake and in the analysis of the nutrient intake of food. For example, the accuracy of the energy content of reported foods and drinks are dependent on the nutrient database from which the energy values are derived. However, errors in the energy content might be anticipated to be random rather than systematic underestimation.

\section{Conclusions}

UR of EI must be taken into account when assessing dietary intake in population-based studies. UR introduces systematic bias and affects not only analyses of the major components of EI, macronutrients, but also of micronutrients and toxic substances in foods. Although this bias cannot be removed in data analysis, it needs to be taken into consideration when interpreting dietary data. Including measurements of physical activity and questions to identify under-eating during the dietary recording period may help in evaluating UR especially when comparing data from different population groups with variable activity levels. Improvements in methods to evaluate UR will help in interpreting diet-health relationships, especially in the context of obesity.

\section{Acknowledgements}

The present study was funded by the Food Standards Agency and the Medical Research Council. We thank Antony Wright for the analyses of the DLW samples and data in the NDNS feasibility study.

\section{References}

Ainsworth BE, Haskell WL, Leon AS, Jacobs DR, Montoye HJ, Sallis JF \& Paffenbarger RS (1993) Compendium of physical activities: classification of energy costs of human physical activities. Med Sci Sports Exerc 25, 71-80.

Ainsworth BE, Haskell WL, Whitt MC, et al. (2000) Compendium of physical activities: an update of activity codes and MET intensities. Med Sci Sports Exerc 32, S498-S504. 
Bandini LG, Schoeller DA, Cyr HN \& Dietz WH (1990) Validity of reported energy intake in obese and nonobese adolescents. Am J Clin Nutr 52, 421-425.

Black AE \& Cole TJ (2000) Within- and between-subject variation in energy expenditure measured by the doubly-labelled water technique: implications for validating reported dietary energy intake. Eur J Clin Nutr 54, 386-394.

Black AE, Prentice AM, Goldberg GR, Jebb SA, Bingham SA, Livingstone MBE \& Coward WA (1993) Measurements of total energy ependiture provide insights into the validity of dietary measurements of energy intake. J Am Diet Assoc 93, 572-579.

Borrud L, Wilkinson-Enns C \& Mickle S (1997) What we eat: USDA surveys food consumption changes. In Community Nutrition Institute Nutrition Week, April 18 edition, pp. 4-5 Washington, DC: Community Nutrition Institute.

Bratteby L-E, Sandhagen B, Fan H \& Samuelson G (1997) A 7-day diary for assessment of daily energy expenditure validated by the doubly labelled water method in adolescents. Eur J Clin Nutr 51, 585-591.

Briefel RR, Sempos CT, McDowell MA, Chien S \& Alaimo K (1997) Dietary methods research in the third National Health and Nutrition Examination Survey: underreporting of energy intake. Am J Clin Nutr 65, 1203S-1209S.

Goldberg GR, Black AE, Jebb SA, Cole TJ, Murgatroyd PR, Coward WA \& Prentice AM (1991) Critical evaluation of energy intake data using fundamental principles of energy physiology: 1 . Derivation of cut-off limits to identify under-reporting. Eur $J$ Clin Nutr 45, 569-581.

Goris AHC, Westerterp-Plantenga MS \& Westerterp KR (2000) Undereating and underreporting of habitual food intake in obese men: selective underreporting of fat intake. Am J Clin Nutr 71, $130-134$.

Heitmann BL \& Lissner L (1995) Dietary underreporting by obese individuals - is it specific or non-specific? Br Med J 311, 986-989.

Henderson L, Gregory J, Irving K \& Swan G (2002) The National Diet and Nutrition Survey: Adults Aged 19 to 64 Years, vol. 2: Energy, Protein, Carbohydrate, Fat and Alcohol Intake. London: The Stationery Office.

Huang T, Roberts SB, Howarth NC \& McCrory MA (2005) Effect of screening out implausible energy intake reports on relationships between diet and BMI. Obesity Research 13, 1205-1217.

Institute of Medicine of the National Academies (2002) Dietary Reference Intakes for Energy, Carbohydrate, Fiber, Fat, Fatty Acids, Cholesterol, Protein, and Amino Acids. Washington, DC: National Academies Press.

Johansson L, Solvoll K, Bjorneboe G \& Drevon C (1998) Under- and overreporting of energy intake related to weight status and lifestyle in a nationwide sample. Am J Clin Nutr 68, 266-274.

Lafay L, Basdevant A, Charles MA, Vray M, Balkau B, Borys JM, Eschwege E \& Romon M (1997) Determinants and nature of dietary underreporting in a free-living population: the Fleurbaix Laventie Ville Sante (FLVS) Study. Int J Obes Relat Metab Disord 21, 567-573.
Lichtman SW, Pisarska K, Berman ER, Pestone M, Dowling H, Offenbacher E, Weisel H, Heshka S, Matthews DE \& Heymsfield SB (1992) Discrepancy between self-reported and actual caloric intake and exercise in obese subjects. New Engl J Med 327, $1893-1898$.

Livingstone MBE \& Black A (2003) Markers of the validity of reported energy intake. J Nutr 133, Suppl. 3, 895S-920S.

Livingstone MBE, Coward WA, Prentice AM, Davies PSW, Strain JJ, McKenna PG, Mahoney CA, White JA, Stewart CM \& Kerr M-JJ (1992) Daily energy expenditure in free-living children: comparison of heart-rate monitoring with the doubly labeled water method. Am J Clin Nutr 56, 343-352.

Livingstone MBE, Prentice AM, Strain JJ, Coward WA, Black AE, Barker ME, McKenna PG \& Whitehead RG (1990) Accuracy of weighed dietary records in studies of diet and health. Br Med J 300, 708-712.

Murgatroyd PR, Shetty PS \& Prentice AM (1993) Techniques for the measurement of human energy expenditure: a practical guide. Int $J$ Obes Relat Metab Disord 17, 549-568.

Norris J, Harnack L, Carmichael S, Pouane T, Wakimoto P \& Block G (1997) US trends in nutrient intake: the 1987 and 1992 National Health Interview Surveys. Am J Public Health 87, 740-746.

Prentice AM, Black AE, Coward WA, Davies HL, Goldberg GR, Murgatroyd PR, Ashford J, Sawyer M \& Whitehead RG (1986) High levels of energy expenditure in obese women. $\mathrm{Br}$ Med $\mathrm{J}$ 292, 983-992.

Pryer J, Vrijheid M, Nochols R, Kiggins M \& Elliott P (1997) Who are the 'low energy reporters' in the dietary and nutritional surveys of British adults? Int J Epidemiol 26, 146-154.

Rennie KL, Jebb SA, Wright A \& Coward WA (2005) Under-reporting of energy intake in the National Diet and Nutrition Survey of young people. Br J Nut 93, 241-247.

Schoeller DA (2002) Validation of habitual energy intake. Public Health Nutr 5, 883-888.

Schoeller DA \& van Santen E (1982) Measurement of energy expenditure in humans by doubly labeled water method. $J$ Appl Physiol 53, 955-959.

Smith WT, Webb KL \& Heywood PF (1994) The implications of underreporting in dietary studies. Aust J Public Health 18, 311-314.

Social Survey Division of the Office of National Statistics Bates CJ, Quigley R, Birch M, Coward WA and Prentice A, (2002) Appendix C. Feasibility Study Report. The National Diet and Nutrition Survey: adults aged 19 to 64 years, Accessed 19 Novermber 2006. http://www.food.gov.uk/multimedia/pdfs/ndnsc.pdf.

Voss S, Kroke A, Klipstein-Grobusch K \& Boeing H (1998) Is macronutrient composition of dietary intake data affected by underreporting? Results form the EPIC-Potsdam Study. Eur J Clin Nutr 52, 119-126.

Westerterp KR \& Goris AHC (2002) Validity of the assessment of dietary intake: problems of misreporting. Curr Opin Clin Nutr Metab Care 5, 489-493. 